\title{
NOTAS
}

\section{LA PÉRDIDA DE VOCALES ÁTONAS EN LA ALTIPLANICIE MEXICANA}

Uno de los rasgos fonéticos más llamativos de la altiplanicie mexicana, con su fuerte consonantismo, es la abreviación o pérdida completa de vocales inacentuadas, sobre todo finales, en la conversación animada. De este fenómeno, por cierto no exclusivo de México, aunque muy típico de él, hablan Pedro Henríquez Ureña (BDH, IV, págs. 222, nota, y 336) y Joseph Matluck (en este mismo número de NRFH, pág. 113). Pero nos parece importante observar que la pérdida de estas vocales inacentuadas ocurre casi exclusivamente en contacto con $s$, sobre todo entre $s$ y otra consonante sorda, o con $s$ en final de palabra. Parece que la $s$ mexicana, siempre larga y de timbre agudo (y más todavía en final de palabra), provoca el ensordecimiento de la ya abreviada vocal y en ciertos casos la asimila por completo ${ }^{1}$. Cuando sucede así, creemos haber notado con frecuencia, aunque no siempre, un alargamiento compensatorio de la $s$, la cual puede o no convertirse entonces en una $s$ silábica, por ejemplo: $p$ 'scar 'pescar'.

En Guanajuato hemos notado en el habla de todas las clases sociales, pero sobre todo en el habla rápida y nerviosa de los mineros, ejemplos como doscient's, trescient's pes's, Lop's 'López', Velask's 'Velázquez', much ${ }^{u}$ s chok's y aksident's 'muchos choques y accidentes', Aw $w^{a}$ scalient's 'Aguascalientes', $p$ 's 'ntons's 'pues entonces', croksi 'creo que si', camp'sinos, emp'zar, veint'cinco, viej'cito, cam'sita, vis'tamos, a p'sar d'es's temporales, los tren's ${ }^{2}$, lo sut $^{u}$ pim's 'lo supimos ac'stumbro, pas'sté 'pase usted', nes's'tamos, s'pongo k'si.

Entre los campesinos de la Barranca de Atotonilco el Grande (estado de Hidalgo) pude observar poquit's, Venat's 'Venados', nopal's, p’scar. En el Valle de México la señora Estrella Cortichs de

1 En realidad hay dos $s$ en el altiplano, la predorsal dentoalveolar convexa de la Capital y del Valle de México, "singular por su longitud entre todas las del mundo hispánico" (Henríquez Ureña, BDH, IV, pág. 396), y la coronal dentoalveolar plana, muy fuerte y larga también, que parece predominar sobre la primera por lo menos en parte del estado de Guanajuato. Esta última es la misma que se oye, pero menos aguda y menos larga, en el Norte de México, por ejemplo en Chihuahua.

${ }^{2}$ Entre la $n$ y la $s$ se desarrolla una ligera oclusión sorda: los $\operatorname{tren}^{t} s$. 
Mora recogió nesita 'necesita', y nesidad 'necesidad' [en realidad nes'sita, nes'sidá] (cf. su tesis El habla de Tepotzotlán, México, 1951, pág. 26). A. R. Nykl oyó croksi 'creo que sí' en Tlaxcala (BDH, IV, 221), y expresiones como viej'sito, psioso 'precioso' [en realidad ps:ioso], pas-sté, ques-sede 'qué sucede' y blocs prapunts 'bloques para apuntes' las oyó en la Capital Henríquez Ureña (loe. cit.). Para la Capital podremos agregar láp'z, taquit's chiquit's, quiñent's, Insurgent's, $p_{1}^{\prime} s i$ 'pues si', San Luis Pot'si' ${ }^{3}$, inteligent's, ant's, est's asunt's, nosot's 'nosotros', zapat's, es's tiemp's, es $s$ gents, ¿cuánt's pagat's? (esto lo dijo un indio que visitaba la ciudad), gras's o gras's 'gracias', las dos $\cos ^{2} s$, sap's que 'sabes que', son muy grant's 'son muy grandes'. ¡Tapet's barat's! lo oí a un vendedor en un mercado de la Capital, quien después de repetirlo varias veces así, cambió su grito en itapetéés baratóós! Sirva este ejemplo para ilustrar un punto muy importante: el que la pérdida total de vocales átonas en contacto con $\mathrm{s}$ es característica del habla rápida más bien que fenómeno general. Con un cambio de tempo, las vocales perdidas reaparecen sin que el hablante se dé cuenta siquiera de que algunas veces las suprime. Para terminar, en ciertos barrios de la ciudad se puede oír a las vendedoras indias de Xochimilco gritar, con voz nasal y aguda: ¿Nóó meercaráán - chichicuiii - lotiiitos vif's? ¿No comprarán chichicuilotitos vivos?' 4 Con excepción de la última, algo rara, tales pronunciaciones se oyen en todas las clases sociales cuando hablan de prisa, tanto en Guanajuato y otras poblaciones como en la $\mathrm{Ca}$ pital.

Según se desprende de los ejemplos citados, la vocal inacentuada breve tiene una marcada tendencia a desaparecer entre $s$ y las oclusivas sordas $p, t, k$, especialmente en final de palabra. Son más raros los casos con otra consonante sorda (viej'cito, entons's) o con nasal (supim's, cam'sita, $l^{o} s$ tren's). De $l$ tengo sólo un ejemplo (nopal's), de $y, r$ y $r r$ ninguno (por ejemplo, no se oye * poy's 'pollos', car's 'caros', carr's 'carros'). Sin embargo, hay dos ejemplos en los cuales una $r$ agrupada desaparece junto con la vocal (psioso 'precioso', nosot's 'nosotros').

De los cuatro ejemplos en que la $s$ ensordece a una consonante sonora (grant's 'grandes', sa's que, Venat's, vif's), sólo los dos primeros son comunes, tal vez por el uso general y frecuente de aquellas palabras. Los otros dos se oyeron sólo entre campesinos.

En cuanto a la vocal perdida, puede ser una $i$, una $e$ (Lop's 'López'), una o (est's asunt's), una $u$ (s'pongo). La a se muestra más resistente. En los casos pertinentes que pudimos observar, la $a$ se relajó mucho $\left({ }^{a},{ }^{\circ}\right)$, pero rara vez desapareció por completo: se oía aún un ligero elemento vocálico. Por ejemplo $A w^{a}$ scalient's o $A w^{\ominus} s$ -

sotsi se oye también en las sierras de Bolivia y del Perú.

${ }^{4}$ El chichicuilote es un pajarito mexicano que emplean las clases humildes en sus casas para cazar moscas. 
calient's, pero no *Auscalient's; ${ }^{2}{ }^{2}$ gent's, pero no ${ }^{*} e s^{\prime} s$ gent's. Exceptuando la fórmula frecuente gras $^{i} s$ o gras's ${ }^{5}$ 'gracias', en la que por desgaste fonético llega a desaparecer no sólo la $a$, sino el diptongo entero, la única vez que creímos notar la pérdida total de una $a$ fué en el habla de un ingeniero de minas de Guanajuato: est's milp's 'estas milpas'.

Yale University.

Peter Boyd-Bowman

\section{EL SUFIJO -AL EN EL ESPAÑOL DE GUATEMALA}

Entre los fenómenos lingüísticos que observé en Guatemala durante una estancia de ocho meses, me llamó la atención la extraordinaria vitalidad del sufijo -al. En las páginas que siguen estudio los usos que allí tiene este sufijo, e intento dar las razones de su vitalidad ${ }^{1}$.

En todas partes del mundo hispánico se usa -al (-ar) ${ }^{2}$ para formar sustantivos. Su significación más corriente es la de 'lugar poblado de árboles o plantas' (pinar, tomatal). También puede denotar 'árbol' (nogal, peral), aunque no es frecuente este uso ${ }^{3}$. Finalmente, en algunas palabras indica 'abundancia' (dineral, pizarral). Estos tres usos normales se han extendido y especializado en Guatemala. Presento mis ejemplos ${ }^{4}$ bajo cinco encabezados, según que el sufijo indique: I) planta; 2) planta o conjunto de plantas en un lugar; 3) conjunto de plantas exclusivamente; 4) lugar o abundancia, y 5) aumentativo.

"Cuando hay encuentro de dos $s$, una es siempre silábica. En es's, gras's, entons's no tenemos una $s$ larga y uniforme (*entons:), sino dos: la división silábica entre ellas va marcada por un ligero y brevísimo relajamiento de la sibilación, sin que ésta deje de ser continua y sorda. Con una $s$ fuerte y continua (*es:, * gras:), las palabras quedarían extrañamente alteradas.

${ }^{2}$ Sobre -al se ha escrito muy poco. El único artículo que conozco sobre este tema es el de M. L. WAGNER, "Zum spanisch-portugiesischen Suffix -al", en $V K R$, III, 1930, págs. 87-92. Los estudios sobre el español de América no consignan usos de -al desconocidos en la lengua literaria.

${ }^{2}$ El trueque de la $l$ final de sílaba por $r$ no es corriente en la fonética guatemalteca. En general, -ar parece usarse por -al sólo para evitar la reduplicación de la $l$ en palabras como coyolar, roblar, etc.

${ }^{3}$ Sólo en el Noroeste de España parece ser frecuente. Véanse, por ejemplo, los estudios de Guzmán Álvarez, El habla de Babia y Laciana, Madrid, 1949, pág. 240; Mạ Concepcrón Casado Lobato, El habla de la Cabrera Alta, Madrid, 1948, pág. 69; Mạ Josefa Canellada, El bable de Cabranes, Madrid, 1944, pág. 27: Santiago Alonso Garrote, El dialecto vulgar leonés hablado en Maragateria y tierra de Astorga, 2a ed., Madrid, 1947, pág. 74; Antonro Llorente. Maldonado de Guevara, Estudio sobre el habla de la Ribera, Salamanca, 1947, pág. 126 .

- Muchos de ellos los recogí directamente de los hablantes. Los más están registrados por dos autores: Lisandro Sandoval, Diccionario de guatemaltequismos, 2 vols., Guatemala, 1941*1942, y ANToNIo BATREs JÁuregur, Vicios del lenguaje y provincialismos de Guatemala, Guatemala, 1892, a quienes designaré en lo sucesivo con las iniciales $\mathrm{S}$ y $\mathrm{B}$. 